\title{
Letter to the Editor: Is Anterior-Only Fixation Adequate for Three-Column Injuries of the Cervical Spine?
}

\author{
Vibhu Krishnan Viswanathan ${ }^{1}$, Surabhi Subramanian ${ }^{2}$ \\ ${ }^{1}$ Department of Spine Surgery, Ganga Hospital, Coimbatore, India \\ ${ }^{2}$ Department of Radiodiagnosis, Ganga Hospital, Coimbatore, India
}

Dear editor,

We read with interest the article "Is anterior-only fixation adequate for three-column injuries of the cervical spine?" by Sethy et al. [1]. It is an informative article, and the authors have retrospectively analyzed the surgical outcomes of 21 patients, who underwent anterior-only surgery for three-column injuries of the cervical spine. Although we commend the efforts of the authors, we have some queries that need to be addressed:

(1) Although the AO classification is a comprehensive classification for thoracolumbar (TL) injuries, its description of the sub-axial cervical spine injuries (CSIs) has some limitations. Type $\mathrm{C}$ fractures, unlike those in TL injuries, include a highly heterogenous group of injuries. Therefore, the classification includes certain modifiers describing the posterior ligamentous complex and facet injuries. The outcome and management of these vastly distinct types of fractures are not similar. Therefore, a blanket classification of cervical fractures as in "three column injuries" or "AO type C" injuries is insufficient.

(2) A stable rigid fixed-angle construct is usually recommended to protect the cervical spine against deforming kyphotic forces following unstable CSIs. The major con- cerns regarding isolated anterior surgeries after bilateral facet dislocations include the extent of posterior ligamentous injuries and loss of tension band effects. Such major posterior injuries result in progressive loss of reduction, loss of alignment, and postoperative kyphosis. Previous studies have reported such mechanical complications in $8 \%-13 \%$ of patients undergoing anterior-only fixation after bilateral facet dislocations $[2,3]$. The authors have not stratified the cervical injuries in detail, indicating that different types of injuries were included under the same category. In our opinion, this is a major disadvantage.

(3) The current AO classification does not include subtypes of $\mathrm{C}$ injuries (and not C1-3 types) but includes additional modifiers including the bilaterality of injuries and facet injuries (F1-4). However, these factors have not been discussed in the manuscript.

(4) The major risk factors for such failures after anterior-only stabilization include the presence of associated significant bony injuries (facet [ $>50 \%]$, lateral mass, or endplate fractures); osteoporosis; and ankylosing spondylitis [4]. These subsets of patients can have poorer surgical outcomes and higher chances of mechanical failure.

In the images provided, one of the patients presented with unifacet dislocation, whereas the other two patients

Received Mar 28, 2021; Accepted Mar 30, 2021

Corresponding author: Vibhu Krishnan Viswanathan

Department of Spine Surgery, Ganga Hospital, 313, Mettupalayam Road, Coimbatore, Tamil Nadu 641043, India

Tel: +91-7358622093, E-mail: drvibu007@gmail.com 
presented with bifacet dislocation (without any fractures). Can the authors discuss more on the presence of additional aforementioned risk factors in their patients?

(5) Considering these aforementioned reasons, we do think that some sub-sections of CSIs certainly require posterior reinforcement (in addition to anterior procedures). The main problem of this study is that the authors have grouped different fracture patterns together and have concluded that anterior-only surgeries for all types of three-column CSIs will suffice. More detailed information is needed for the readers to understand better.

We once again congratulate the authors for presenting this interesting study and thank them for their efforts.

\section{Conflict of Interest}

No potential conflict of interest relevant to this article was reported.

\section{Author Contributions}

Manuscript Preparation: Vibhu Krishnan Viswanathan; Participant evaluator: Surabhi Subramanian.

\section{References}

1. Sethy SS, Ahuja K, Ifthekar S, Sarkar B, Kandwal P. Is anterior-only fixation adequate for three-column injuries of the cervical spine? Asian Spine J 2021;15:7280.

2. Johnson MG, Fisher CG, Boyd M, Pitzen T, Oxland TR, Dvorak MF. The radiographic failure of single segment anterior cervical plate fixation in traumatic cervical flexion distraction injuries. Spine (Phila $\mathrm{Pa}$ 1976) 2004;29:2815-20.

3. Anissipour AK, Agel J, Baron M, Magnusson E, Bellabarba C, Bransford RJ. Traumatic cervical unilateral and bilateral facet dislocations treated with anterior cervical discectomy and fusion has a low failure rate. Global Spine J 2017;7:110-5.

4. Mubark I, Abouelela A, Hassan M, Genena A, Ashwood N. Sub-axial cervical facet dislocation: a review of current concepts. Cureus 2021;13:e12581. 